\title{
Irritable Bowel Syndrome Patients Exhibit Depressive and Anxiety Scores in the Subsyndromal Range
}

\author{
Sean D. Hood ${ }^{*}, \mathrm{a}, \mathrm{b}$, Jonathan Q. Shufflebotham ${ }^{\mathrm{c}}$, Julie Hendry ${ }^{\mathrm{b}}$, Dana A. Hince ${ }^{\mathrm{a}}$, Ann S. Rich ${ }^{\mathrm{b}}$, \\ Chris S.J. Probert ${ }^{\mathrm{c}}$ and John Potokar ${ }^{\mathrm{b}}$ \\ ${ }^{a}$ School of Psychiatry \& Clinical Neurosciences (M521), University of Western Australia, QEII Medical Centre, Perth \\ 6009, Australia \\ ${ }^{b}$ Psychopharmacology Unit, University of Bristol, Dorothy Hodgkin Building, Whitson Street, Bristol BS1 8NY, UK \\ ${ }^{c}$ Clinical Science at South Bristol, University of Bristol, Bristol, BS2 8AE, UK
}

\begin{abstract}
Irritable bowel syndrome (IBS) patients frequently experience affective disorders and psychiatric outpatients frequently meet criteria for IBS. The exact nature of this co-morbidity is not clear. 34 patients with Rome-II diagnosed IBS were recruited from a Gastroenterology clinic. Patients with social anxiety disorder (10 SSRI-remitted and 7 untreated subjects) were used as a psychiatric comparison, 28 normal subjects from our register were included as a fourth group (Volunteers). Depressive and anxiety symptoms were measured by the Beck Depression Inventory (BDI) and Spielberger Trait Anxiety Inventory (STAI), respectively. Personality traits were measured with the Swedish universities Scales of Personality (SSP). IBS subjects had BDI and STAI scores intermediate between those of volunteers and patients, despite their lack of a co-morbid psychiatric diagnosis. A principle component factor analysis of the SSP dataset corresponded closely to the solution published with other samples. ANOVA revealed significant between-group differences for 7 of the 13 SSP variables.
\end{abstract}

Keywords: IBS, anxiety, depression, subsyndromal, personality.

\section{INTRODUCTION}

Irritable bowel syndrome (IBS) is a common condition, with estimated prevalence rates of $10-15 \%$ [1]. There is considerable evidence for co-morbidity between IBS and affective disorders [2,3] although the relationship is complex [4]. For example in gastroenterology clinics, recently referred IBS patients have more anxiety than depressive symptoms [5], whereas more chronic attendees have less anxiety than depression [6]. The reasons for this are likely confounded by factors such as age, chronicity, help-seeking behaviours and family history [7-9].

Functional somatic syndromes, including IBS, have been shown to be associated with depression or anxiety at a higher rate than either healthy controls or subjects with phenomenologically-similar medical complaints of known organic pathology [3].

Personality factors in IBS have been relatively understudied, and the first study to recruit subjects from a representative community sample with physician diagnosis was only recently published [10]. This study compared IBS patients, IBS non-consulting subjects and normal controls recruited from the Swedish population registry using the Karolinska Scales of Personality (KSP) and Symptom Checklist 90

*Address correspondence to this author at the School of Psychiatry \& Clinical Neurosciences (M521), University of Western Australia, QEII Medical Centre, Perth 6009, Australia;

E-mail: sean.hood@uwa.edu.au
(SCL-90). IBS subjects who had not consulted a physician had similar scores to IBS patients on most measures; both IBS groups differed from controls on personality, interpersonal, and psychological distress measures.

A clearer understanding of the personality and negative affectivity characteristics of IBS patients is essential to ensure targeted and effective treatments for this condition. This is especially important given that both pharmacotherapy (SSRIs) and psychological treatments (Cognitive Behavioural Therapy - CBT) that are mainstream treatments for mood disorders are being increasingly used in IBS with some efficacy $[11,12]$.

The aim of the present study was to assess personality using an enhanced version of the KSP in a well defined group of IBS patients attending an outpatient gastroenterology service. We wanted to compare personality and negative affectivity ratings with a well defined physician diagnosed group of patients with an anxiety disorder and an age matched volunteer group. A cohort of patients with untreated and treated social anxiety disorder (SAnD) was available to us at the time this study was conducted. This provided a convenient anxiety disorder comparator that reflected the full range of clinical anxiety severity. Our clinical and research experience $[13,14]$ is that patients with untreated SAnD exhibit very high levels of anxiety as measured by the assessment scales used here.

Our hypotheses were that IBS patients would be more anxious and have higher depression scores than volunteers 
but lower than untreated SAnD patients. If correct this would support the common clinical observation that IBS patients, whilst not suffering from clinically significant psychopathology, may experience subsyndromal mood/anxiety symptoms and personality traits that may be relevant to treatment options and clinical outcome.

\section{MATERIALS AND METHODOLOGY}

\section{Subjects}

All of the subjects in this study (see Table 1 for numbers) had agreed to participate in a series of studies investigating the role of the monoamine systems in either SAnD or IBS. The local regional ethics committee approved these studies; supplemental results will be presented in future papers. The IBS patients were recruited by JQS from a gastroenterology outpatient clinic held at the Bristol Royal Infirmary (ie: IBSconsulters). Patients with SAnD came from the Psychopharmacology Unit outpatient department at the same hospital and were under the clinical care of SDH and JP. The normal volunteers were recruited from a volunteer register held at the Psychopharmacology Unit. All subjects, including volunteers, were assessed for medical and psychiatric comorbidity prior to entry into this study by clinical interview (JH) and supplementary rating scales as indicated; co-morbid subjects were excluded. No subject had a current or recent (6 months) co-morbid DSM-IV diagnosis, or other significant medical condition. Remitted SanD subjects were taking a serotonergic medication (paroxetine); no other subjects were taking a serotonergic or psychotropic medication. Subjects were not paid for their participation, and decision to enter into the study did not influence clinical care.

Bowel habit was assessed according to Rome II Criteria, and IBS subtype classified as constipation-predominant (CIBS), diarrhoea-predominant (D-IBS), or alternating (A-IBS) according to established convention [15].

\section{Measures} view.

Basic demographic data were collected by clinical inter-

Depressive symptoms in the studies were measured by the Beck Depression Inventory (BDI) [16]. Trait anxiety was recorded using the Spielberger State-Trait Anxiety Inventory, Trait Scale (STAI) [17].

Personality traits were measured with the Swedish universities Scales of Personality (SSP) [18]. The SSP is a shortened and psychometrically enhanced version of the Karolinska Scales of Personality (KSP) [19] that improves upon face validity, internal consistency and response differentiation. The SSP contains 91 items divided into 13 scales with seven items each: Somatic Trait Anxiety, Psychic Trait Anxiety, Stress Susceptibility, Lack of Assertiveness, Detachment, Embitterment, Trait Irritability, Mistrust, Impulsiveness, Adventure Seeking, Social Desirability, Verbal Trait Aggression, and Physical Trait Aggression. The items are rated on a 4-point Likert scale, where $1=$ "Does not apply at all", 2= "Does not apply very well", 3= "Applies pretty much" and $4=$ "Applies completely". The SSP was standardized in a representative national sample of 741
Swedes in which Cronbach's alpha values varied between 0.59 and 0.84 . The three-factor solution in the original publication corresponds to well-known personality theories [20]: Factor 1 is related mainly to Neuroticism, Factor 2 is related to Aggressiveness and Factor 3 forms a broad Extraversion factor. This structure has recently been confirmed in a large community sample of women [21].

Normative standard scores ( $T$-scores) are calculated for each gender separately. In the original work the $T$-scale is constructed to have a mean of 50 and a SD of 10 . Our clinicians have consistently found it to be more useful to construct the $T$-scale with a mean of 0 using the same standard deviation of 10. In this method, the magnitude as well as direction of deviation from the mean is more apparent in graphical representations, and we can more easily convey these results to our patients. This latter method is used in this article.

\section{Statistical Analyses}

The statistical analysis was conducted using SPSS v11.5 for Windows (SPSS Inc, Chicago, IL, USA). An alpha level of 0.05 was used, with the Bonferroni adjustment applied to all pair wise tests. Confidence intervals are displayed where available. Waller-Duncan post-hoc analysis, with Type I/Type II Error Seriousness Ratio $=100$, was also used to elucidate homogeneous subsets [22].

Principal components factor analysis was performed on the complete SSP data set. The Kaiser criterion was applied to exclude eigenvalues less than 1 and the scree plot was reviewed. Orthogonal (Varimax) rotation was undertaken and the limit for factor loadings set to 0.45 , as in other analyses of SSP data [23].

Levene's Test was used to verify equality of variances; non parametric tests are used when equality is not demonstrated. Two-sided tests are employed throughout. Pearson correlation co-efficients were reported after examining scatter plots.

\section{RESULTS}

\section{Characteristics of the Sample}

Demographic data from the 79 subjects in this study are presented in Table $\mathbf{1}$. There were significantly more men than women in the SAnD pre treatment group $\left(X^{2}=7, \mathrm{df}=1\right.$, $\mathrm{p}=0.008$ ), and more women than men in the C-IBS ( $X$ $\left.{ }^{2}=4.455, \mathrm{df}=1, \mathrm{p}=0.035\right)$ subgroup. No significant impact of sex on BDI (Kruskal-Wallis $X^{2}=2.122, \mathrm{df}=1, \mathrm{p}=0.145$ ) or STAI (Kruskal-Wallis $X^{2}=0.412, \mathrm{df}=1, \mathrm{p}=0.521$ ) was seen. There was no difference in age between any subject group, and the age of this sample was remarkably similar to the mean age of 40.9 years $(S D=12.7)$ cited in the SSP validation data [18]. Only two IBS patient met criteria for the AIBS group; this small group was thus excluded from subsequent statistical analyses.

\section{BDI}

Significant between-group differences were shown for BDI means $(F[3,42]=12.025, p<0.001)$. Volunteers had the lowest scores, which were significantly less than those of 
IBS subjects $(\mathrm{p}=0.019,95 \% \mathrm{CI}=-0.75$ to -12.48$)$, post treatment SAnD ( $\mathrm{p}=0.01,95 \% \mathrm{CI}=-3.47$ to -16.89$)$ and pre treatment $\mathrm{SAnD}$ groups $(\mathrm{p}<0.001,95 \% \mathrm{CI}=-7.79$ to -22.58$)$. IBS patients also had significantly lower scores than pre treatment SAnD groups $(\mathrm{p}=0.005,95 \% \mathrm{CI}=-1.93$ to -15.20$)$. No other between-group (Bonferroni-adjusted) comparison reached statistical significance. There was no relationship between age $(r=-0.155, p=0.305)$ or $\operatorname{sex}(Z=-1.424$, $\mathrm{p}=0.154$ ) and BDI. Waller-Duncan analysis confirms the trend suggested in Fig. (1) of three distinct subgroups at alpha $=0.05$; namely a volunteer group $($ mean $=1.70)$, a combined IBS and SAnD post treatment group (means $=8.32$, 11.88 respectively), and a SAnD pre- treatment group (mean $=16.88$ ).

Table 1. Demographic Details

\begin{tabular}{|l|c|c|c|}
\hline \multicolumn{1}{|c|}{ Subject Group } & n & Sex & Mean Age (95\% CI) \\
\hline \hline Volunteers & 28 & $18 \mathrm{f} / 10 \mathrm{~m}$ & $35.17(29.19-41.14)$ \\
\hline IBS & 34 & $24 \mathrm{f} / 14 \mathrm{~m}$ & $38.76(34.93-42.60)$ \\
\hline - IBS Constipation $(C-I B S)$ & 11 & $9 \mathrm{f} / 2 \mathrm{~m} *$ & $36.64(30.05-43.22)$ \\
\hline - IBS Diarrhoea $(D-I B S)$ & 21 & $10 \mathrm{f} / 11 \mathrm{~m}$ & $38.86(33.59-44.12)$ \\
\hline - IBS Alternating $(A-I B S)$ & 2 & $2 f / 0 \mathrm{~m}$ & $49.50(-20.38-119.38)$ \\
\hline Post Rx SAnD & 10 & $5 \mathrm{f} / 5 \mathrm{~m}$ & $38.00(30.63-45.37)$ \\
\hline Pre Rx SAnD & 7 & $0 \mathrm{f} / 7 \mathrm{~m} * *$ & $39.00(26.39-51.61)$ \\
\hline & & & \\
\hline Total & 79 & $44 \mathrm{f} / 35 \mathrm{~m}$ & $37.98(35.28-40.69)$ \\
\hline$X^{2}=4.455, \mathrm{df}=1, \mathrm{p}=0.035 ; * * x^{2}=7, \mathrm{df}=1, \mathrm{p}=0.008$.
\end{tabular}

\section{Spielberger Trait}

Significant between-group differences were also seen in STAI scores $(\mathrm{F}[3,42]=11.600, \mathrm{p}<0.001)$. Again, volunteers had the lowest STAI scores, which were lower than those of IBS patients $(\mathrm{p}=0.014,95 \% \mathrm{CI}=-2.24$ to -28.03$)$, post treatment SAnD subjects $(\mathrm{p}<0.001,95 \% \mathrm{CI}=-11.39$ to $40.91)$ and pre treatment $(\mathrm{p}<0.001,95 \% \mathrm{CI}=-13.63$ to 46.17) SAnD subject results (see Fig. 2). IBS subjects results were also less than those of pre treatment SAnD subjects $(\mathrm{p}=0.046,95 \% \mathrm{CI}=-0.17$ to -29.36$)$. There was no effect of age $(\mathrm{r}=-0.149, \mathrm{p}=0.322)$ or $\operatorname{sex}(\mathrm{Z}=-0.563, \mathrm{p}=0.574)$ on STAI. Waller-Duncan analysis yielded three distinct subgroups; viz a volunteer group (mean $=27.55)$, an IBS group $($ mean $=42.68)$, and a combined SAnD post- and pre- treatment group (means $=53.70,57.45$ respectively).

\section{SSP}

The principal component factor analysis for the complete data set is displayed in Table $\mathbf{2}$. Factor 1 consisted of 8 items measuring anxiety and negative emotions that will be referred to as Neuroticism ( $N$ ). Factor 2 consisted of verbal and physical trait aggression and will be referred to as Aggressiveness (A). Factor 3 consisted of impulsiveness and adventure seeking and will be summarised as Sensation Seeking (SS). Cronbach's alpha for these three factors was 0.90, 0.48, 0.57 respectively.

Subgroup factor analyses were not performed due to sample size limitations [24].

One-way ANOVA revealed significant between-group differences for 7 of the 13 SSP variables, viz: Somatic Trait

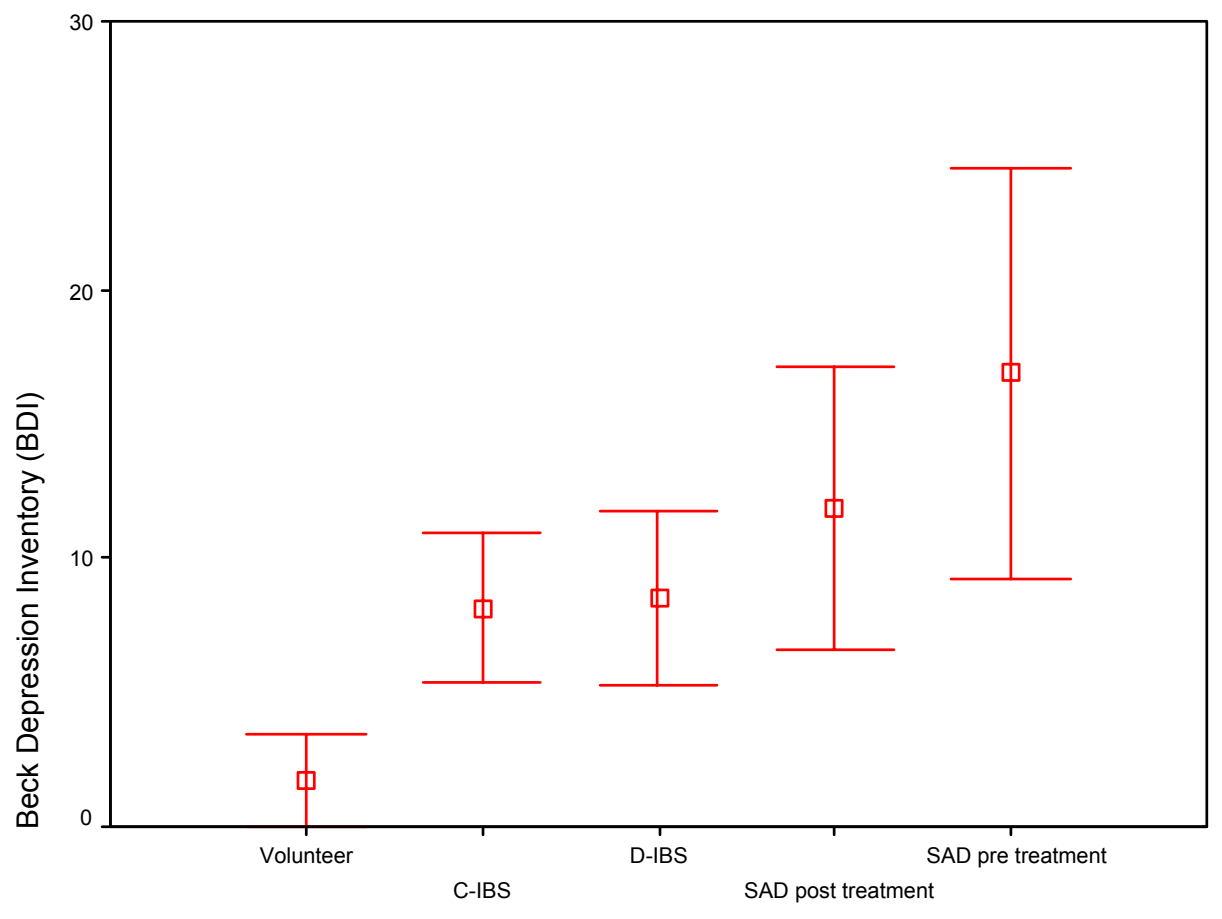

Subject Group

Fig. (1). 95\% Confidence Interval of Beck Depression Inventory Score by Subject Group. 


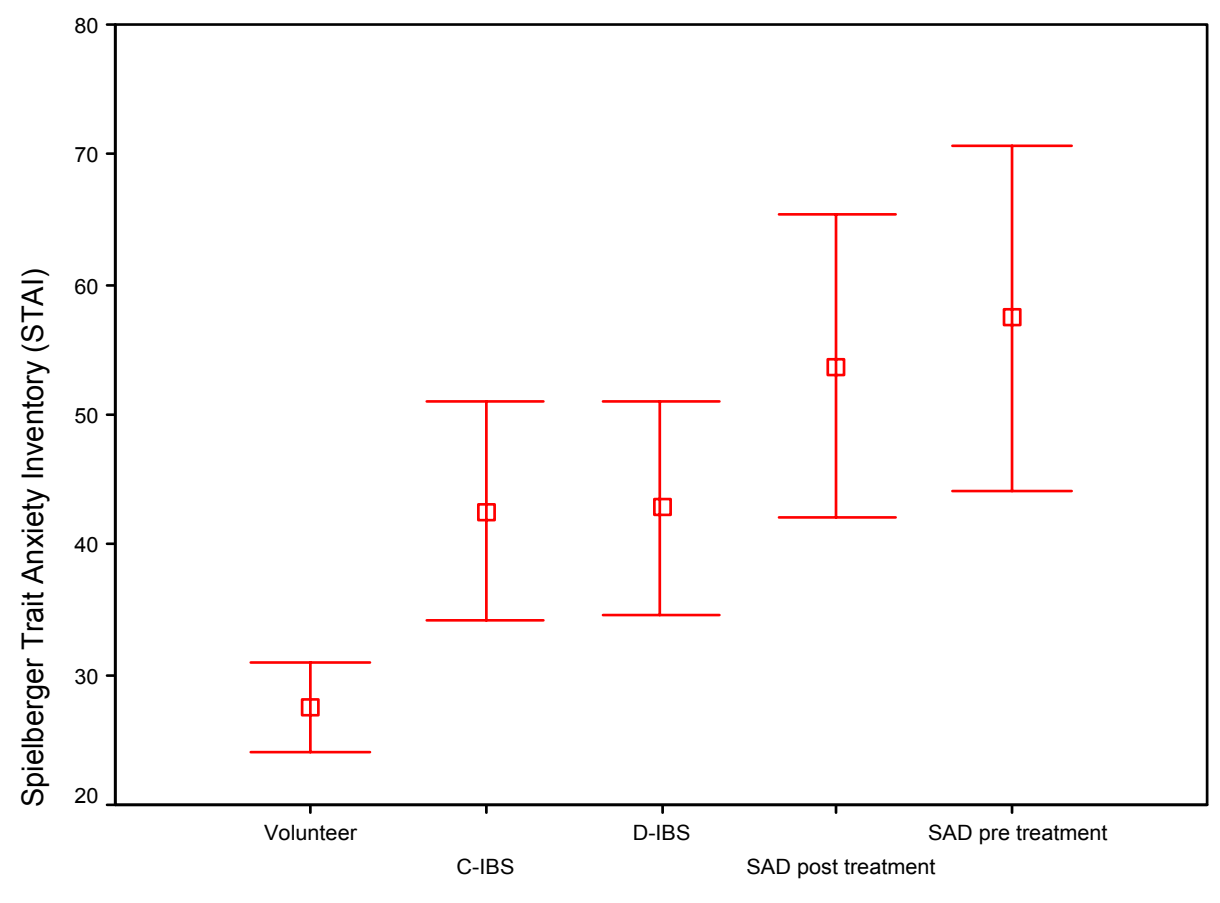

Subject Group

Fig. (2). 95\% Confidence Interval of Spielberger Trait Score by Subject Group.

Anxiety $(\mathrm{F}[3,73]=12.166, \mathrm{p}<0.001)$, Psychic Trait Anxiety $(\mathrm{F}[3,73]=20.048, \mathrm{p}<0.001)$, Stress Susceptibility $(\mathrm{F}[3,73]=$ 18.821, $\mathrm{p}<0.001)$, Lack of Assertiveness $(\mathrm{F}[3,73]=11.030$, $\mathrm{p}<0.001)$, Embitterment $(\mathrm{F}[3,73]=5.712, \mathrm{p}=0.001)$, Trait Irritability $(\mathrm{F}[3,73]=3.625, \mathrm{p}=0.017)$ and Mistrust $(\mathrm{F}[3,73]$ $=12.281, \mathrm{p}<0.001)$. Significant Bonferroni-adjusted pair wise comparisons are shown in Table $\mathbf{3}$, restricted to results involving the IBS patient subgroup. Table 4 presents SSP variables that separate into homogenous subsets at alpha $=$ 0.05 by Waller-Duncan analysis according to subject group.

\section{IBS Subtype Analysis}

There was no difference between C-IBS and D-IBS subjects according to BDI ( $p=0.854,95 \% \mathrm{CI}=-4.291-3.591)$ or STAI $(\mathrm{p}=0.957,95 \% \mathrm{CI}=-11.162-10.595)$. C-IBS subjects scored less on the Lack of Assertiveness scale than did D-IBS subjects (Kruskal-Wallis $X^{2}=4.536, \mathrm{df}=1, \mathrm{p}=0.033$ ), however no other significant differences were demonstrated. The SSP results are presented in Fig. (3).

\section{DISCUSSION}

The BDI and STAI findings reported here confirm our clinical impression that patients with IBS often have anxiety and depressive scores at an intermediate level between normal volunteers and patients with clinical anxiety syndromes such as SAnD. Our results also demonstrate a tendency for IBS patients to experience anxiety at levels less than those seen in patients with SAnD who are currently clinically SSRI-remitted. This may reflect residual vulnerability and / or subsyndromal impairment in SSRI-remitted patients with anxiety disorders such as $\mathrm{SAnD}$.
The relevance of these subsyndromal anxiety and depressive scores in IBS patients is not known. A recent study demonstrated a significant role of chronic life stress as a predictor of IBS symptom intensity over 16 months, but found that BDI or STAI score did not significantly impact upon longitudinal symptom intensity [25].

The mainstays of treatment for anxiety disorders are SSRIs and CBT, both of which are increasingly being used in the management of IBS. The SSRI paroxetine has been shown to improve abdominal pain, constipation and diarrhea associated with IBS, independent of lifetime history of an anxiety disorder [26] although our results suggest that subsyndromal anxiety may be relevant. It is not clear whether SSRI treatment of IBS is reducing this subsyndromal anxiety or whether their mechanism of action is via a direct effect on the gut, and research clearly needs to focus on this.

In terms of CBT, Lackner et al. recently demonstrated that catastrophizing cognitions account for part of the relationship between depression and pain in IBS patients [27] suggesting a complex interplay of physiological, behavioral, and psychological factors. The relationship of IBS to psychological symptoms such as depression is complex, however, with a case report providing evidence that depressive symptoms may be associated with a reduction of IBS symptoms in certain individuals [28].

The SSP questionnaire is an increasingly popular measure of personality structure [21,23,29-31]. Additionally, the authors' have (anecdotally) found it to be a useful measure in routine clinical psychiatric practice [32]. In our experience, patients with anxiety difficulties score positively on the 
Table 2. Principal Component Factor Analysis for Complete Data Set

\begin{tabular}{|c|c|c|c|}
\hline \multirow{3}{*}{ SSP Variable } & \multicolumn{3}{|c|}{ Component } \\
\hline & 1 & 2 & 3 \\
\hline & "Neuroticism" & "Aggressiveness" & $\begin{array}{l}\text { "Sensation } \\
\text { Seeking" }\end{array}$ \\
\hline $\begin{array}{l}\text { Somatic Trait } \\
\text { Anxiety }\end{array}$ & .810 & & \\
\hline $\begin{array}{l}\text { Psychic Trait } \\
\text { Anxiety }\end{array}$ & .905 & & \\
\hline $\begin{array}{l}\text { Stress } \\
\text { Susceptibility }\end{array}$ & .879 & & \\
\hline $\begin{array}{l}\text { Lack of } \\
\text { Assertiveness }\end{array}$ & .861 & & \\
\hline Impulsiveness & & & .800 \\
\hline $\begin{array}{l}\text { Adventure } \\
\text { Seeking }\end{array}$ & & & .807 \\
\hline Detachment & .610 & & \\
\hline Embitterment & .760 & & \\
\hline \multicolumn{4}{|l|}{$\begin{array}{l}\text { Social } \\
\text { Desirability }\end{array}$} \\
\hline $\begin{array}{l}\text { Verbal Trait } \\
\text { Aggression }\end{array}$ & & .818 & \\
\hline $\begin{array}{l}\text { Physical Trait } \\
\text { Aggression }\end{array}$ & & .698 & \\
\hline Trait Irritability & .584 & & \\
\hline Mistrust & .746 & & \\
\hline $\begin{array}{l}\text { Cronbach's } \\
\text { alpha }\end{array}$ & 0.9046 & 0.4848 & 0.5704 \\
\hline
\end{tabular}

Table 3. Bonferroni-Adjusted SSP Pair Wise Comparisons (IBS Subjects Only)

\begin{tabular}{|c|c|c|}
\hline Variable & Relationship & Significance (95\% CI) \\
\hline \hline $\begin{array}{c}\text { Somatic Trait } \\
\text { Anxiety }\end{array}$ & Volunteer $<$ IBS & $\mathrm{p}=0.002(2.62-16.95)$ \\
\hline IBS $<$ SAnD pre treatment & $\mathrm{p}=0.026(-24.07--0.9751)$ \\
$\begin{array}{c}\text { Psychic Trait } \\
\text { Anxiety }\end{array}$ & Volunteer $<$ IBS & $\mathrm{p}=0.024(0.64-13.75)$ \\
& IBS $<$ SAnD post treatment & $\mathrm{p}=0.020(-19.44--1.09)$ \\
IBS $<$ SAnD pre treatment & $\mathrm{p}<0.001(-30.45--9.30)$ \\
\hline Stress & Volunteer $<$ IBS & $\mathrm{p}<0.001(3.66-16.38)$ \\
Susceptibility & IBS $<$ SAnD post treatment & $\mathrm{p}=0.039(-18.10--0.29)$ \\
& IBS $<$ SAnD pre treatment & $\mathrm{p}=0.008(-22.85--2.33)$ \\
\hline Lack of & IBS $<$ SAnD pre treatment & $\mathrm{P}<0.001(-26.23--5.72)$ \\
Assertiveness & IBS $<$ SAnD post treatment & $\mathrm{P}=0.016(-18.98--1.32)$ \\
\hline Mistrust & IBS $<$ SAnD pre treatment & $\mathrm{p}<0.001(-29.42--9.08)$ \\
\hline
\end{tabular}

variables somatic trait anxiety, psychic trait anxiety and stress susceptibility. Moreover, a score above 10 (ie: +1 SD) usually reflects a clinically evident trait and a score above 20 (ie: +2 SD) almost invariably corresponds with a clinically evident impairment. Interestingly, we also find that clinical recovery is mirrored by a normalisation of these SSP variables, making this a useful tool to track progress collaboratively with our patients.

Fig. (4) shows the personality characteristics of IBS patients as measured by SSP. It is clear from this graph that these scores are all within $+/-1$ SD of the general population mean (ie: +/- 10), despite 3 of the 13 scales being

Table 4. SSP Waller-Duncan Homogeneous Subsets

\begin{tabular}{|c|c|c|c|c|}
\hline Variable & \multicolumn{4}{|c|}{ Homogeneous Subset (Harmonic Mean) } \\
\hline Somatic Trait Anxiety & Volunteer $(-5.91)$ & $\begin{array}{c}\text { IBS (3.88) } \\
\text { SAnD post treatment (8.97) }\end{array}$ & SAnD pre treatment $(16.41)$ & \\
\hline Stress Susceptibility & Volunteer $(-0.80)$ & IBS $(9.22)$ & $\begin{array}{c}\text { SAnD post treatment } \\
(18.41) \\
\text { SAnD pre treatment }(21.81)\end{array}$ & \\
\hline Lack of Assertiveness & $\begin{array}{l}\text { Volunteer (0.09) } \\
\text { IBS (3.63) }\end{array}$ & $\begin{array}{l}\text { SAnD post treatment } \\
(12.00)\end{array}$ & SAnD pre treatment $(19.61)$ & \\
\hline Detachment & $\begin{array}{c}\text { Volunteer }(-0.85) \\
\text { IBS }(2.26) \\
\text { SAnD post treatment }(7.41)\end{array}$ & $\begin{array}{c}\text { IBS }(2.26) \\
\text { SAnD post treatment }(7.41) \\
\text { SAnD pre treatment }(13.53)\end{array}$ & & \\
\hline Embitterment & $\begin{array}{l}\text { Volunteer }(0.26) \\
\text { IBS }(2.92)\end{array}$ & $\begin{array}{c}\text { IBS (2.92) } \\
\text { SAnD post treatment (9.09) }\end{array}$ & $\begin{array}{l}\text { SAnD post treatment }(9.09) \\
\text { SAnD pre treatment }(11.98)\end{array}$ & \\
\hline Mistrust & $\begin{array}{l}\text { Volunteer }(-1.50) \\
\text { IBS }(-1.07)\end{array}$ & SAnD post treatment $(9.08)$ & SAnD pre treatment $(18.18)$ & \\
\hline
\end{tabular}

The Waller-Duncan k-ratio t-test compares type I \& type II errors based on Bayesian principles; the chosen ratio of 100 corresponds to alpha $=0.05$. Harmonic means are used as the samples sizes are unequal. As the underlying statistical requirements of Bayesian analyses differ from routine parametric analyses this provides a check of the robustness of the statistical findings - useful with the small sample size available here.

Patient groups appearing in different vertical columns above (viz: homogeneous subsets) are thus statistically distinct at a Bayesian equivalent of alpha $=0.05$. Groups appearing in the same vertical common are not statistically dissimilar. 

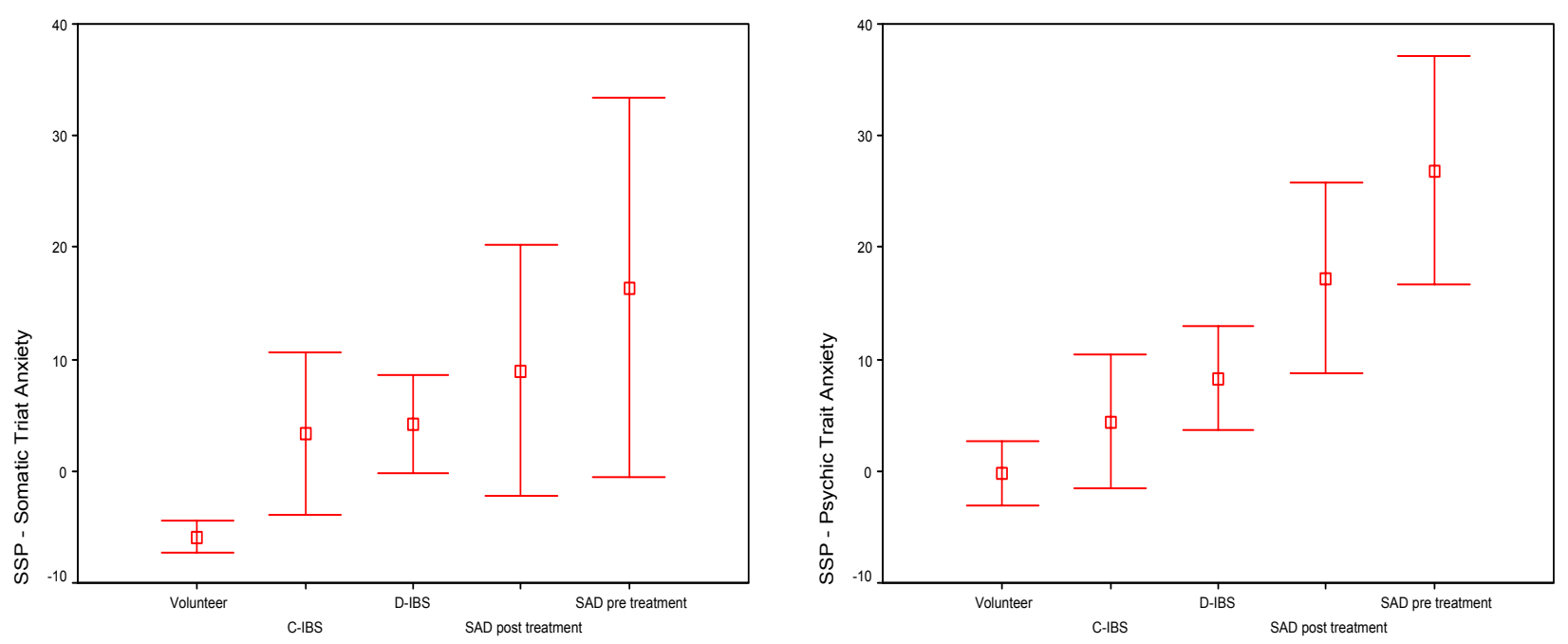

Subject Group

Subject Group
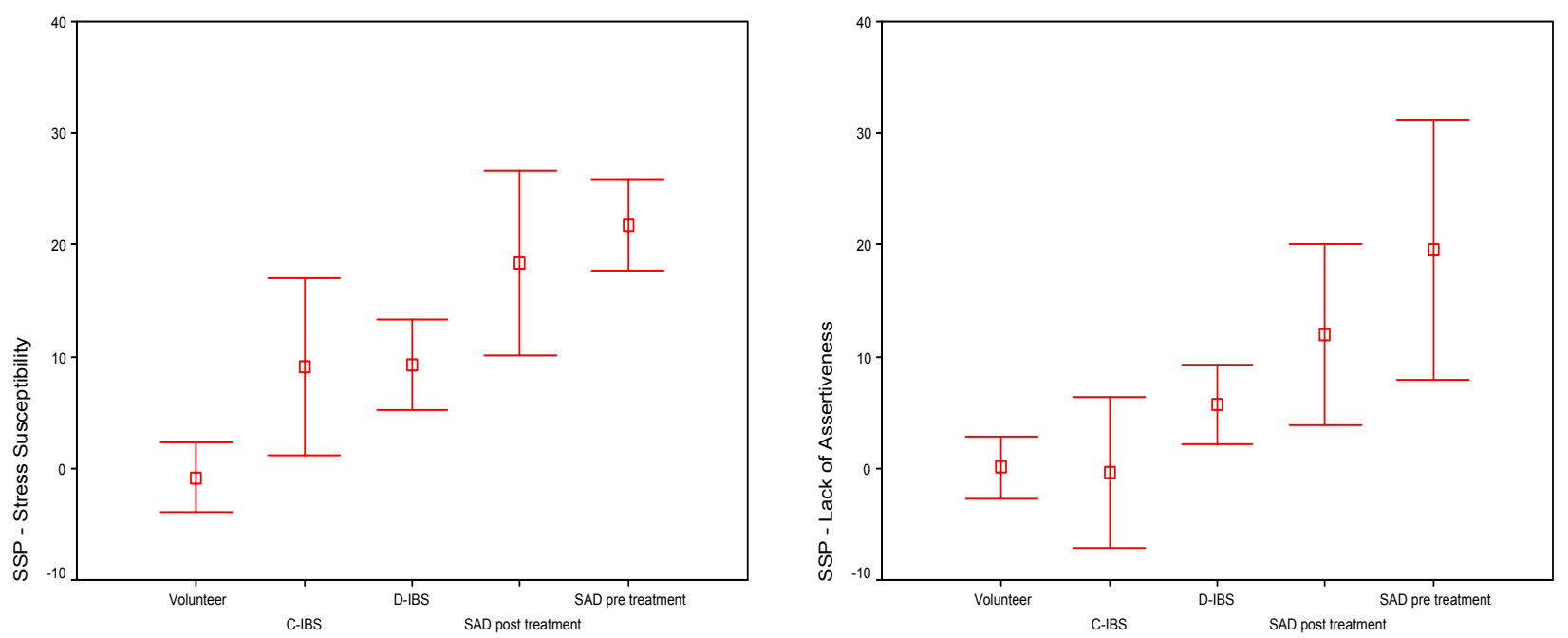

Subject Group

Subject Group
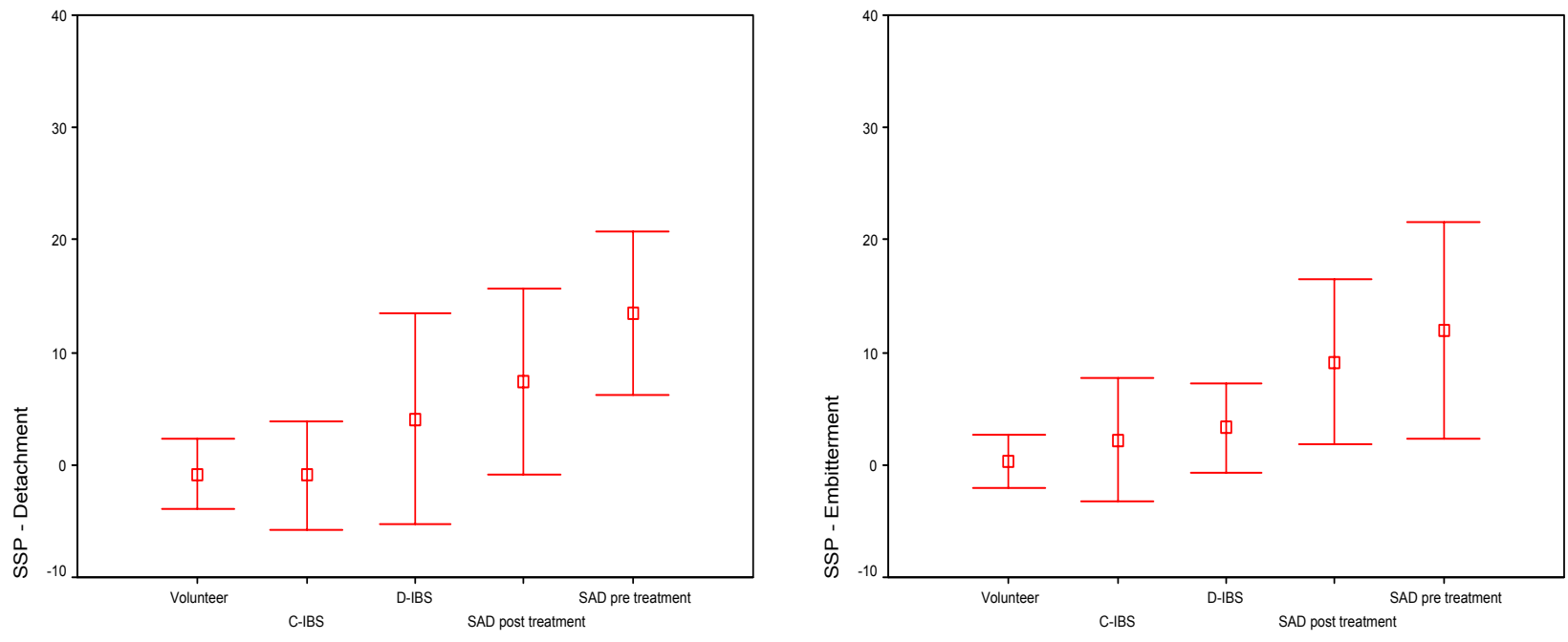

Subject Group

Subject Group 
(Fig. 3) contd.....

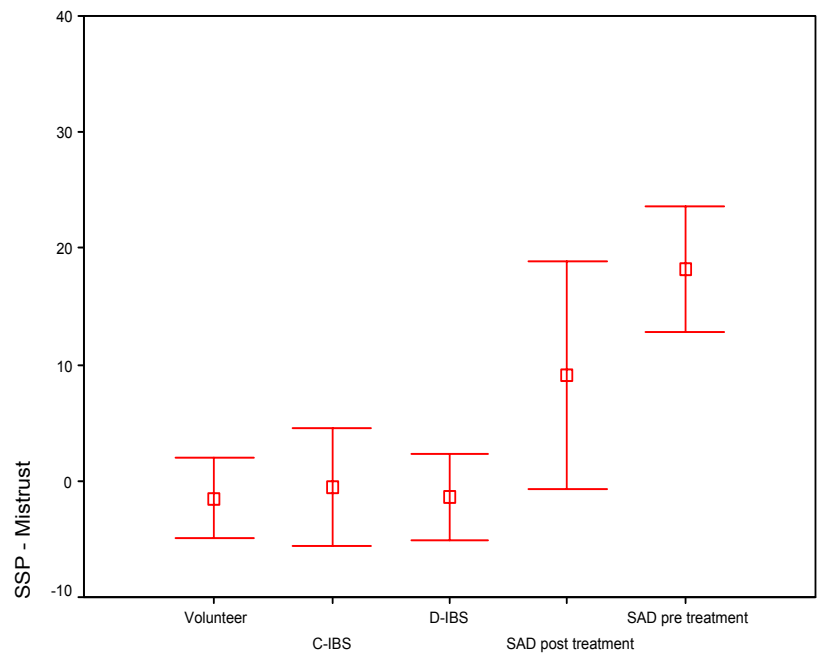

Subject Group

Fig. (3). 95\% Confidence Interval of SSP Variables by Subject Group.

significantly greater than those of our normal volunteers. These three indices (Somatic Trait Anxiety, Psychic Trait Anxiety, and Stress Susceptibility) describe personality aspects closely related to clinical anxiety syndromes, and the SAnD subjects rate particularly high on these. These results concur with the Karolinska Scales of Personality ratings in the Weinryb et al. study that showed higher scores for IBS patients than controls on four of five anxiety proneness scales [10]. Thus, our IBS subjects demonstrated subsyndromal anxiety and depressive symptoms in the context of normal SSP personality profiles. Normal volunteers were screened to ensure the absence of anxiety disorders, which is reflected in their personality profiles.

Treatment seeking for IBS has been associated with an increase in the tendency to make somatic attributions for both gastroenterological symptoms and symptoms characteristic of depression and anxiety states [33]. A logistic regression analysis in a population of nurses showed that subjects reporting a higher degree of neuroticism were at higher risk of being diagnosed with IBS [34]. Additionally, a study of ethnic Chinese subjects found that in patients with IBS the mean depression score of patients who sought any medical consultation was higher than that of those who did not [35]. The degree of anxiety, but not depressive illness was an independent factor associated with health care-seeking behaviour. The results from the SSP instrument in our study showed that IBS subjects had significantly lower levels of both somatic and psychic anxiety variables than SAnD patients with both variables rated at less than 1 SD away from the general population mean.

A recent cluster analysis of IBS treatment non-responders yielded three distinct groups: a psychiatrically-distressed high service utiliser group (group I), a psychiatricallydistressed low service utiliser group (group II), and a tolerant group of low service utilisers (group III) [36]. Group III had

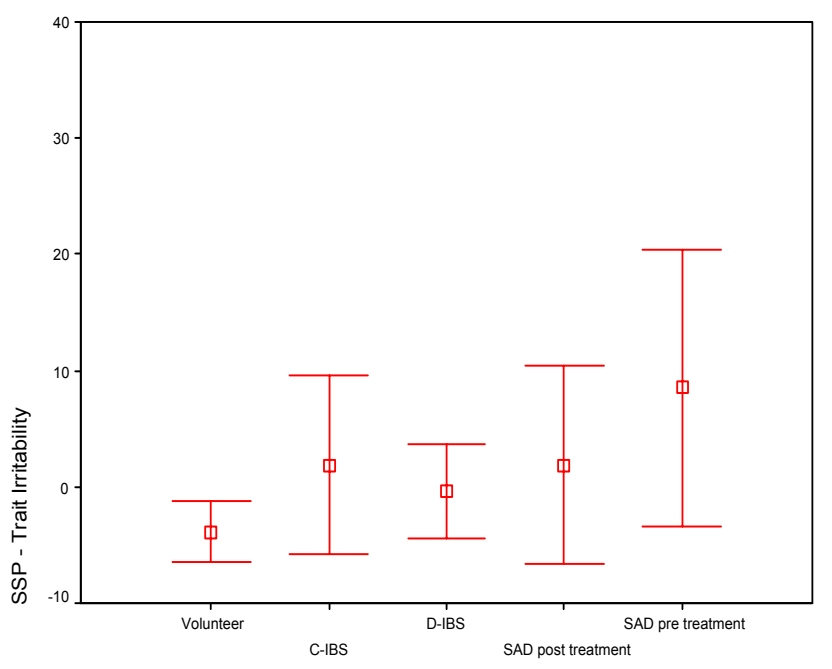

Subject Group

more subjects with C-IBS symptoms than the other groups, and low levels of anxiety, consultation and pain. The IBS subtype analyses performed here produced only one significant finding, namely that C-IBS subjects demonstrated lower Lack of Assertiveness SSP scores than D-IBS patients. Thus, our sample of C-IBS patients was more able to assert themselves in social situations [18] than those with D-IBS symptoms. Just how comparable our C-IBS cohort is to the Group III subjects of the other study is unclear, especially as these patients were less likely to present for treatment.

There are a number of potential limitations of this study that warrant discussion.

This study included IBS patients who were seeking treatment, and who had agreed in principle to take part in a study. No patient with IBS and a co-morbid depressive or anxiety disorder was eligible for inclusion in this study, although only approximately $5 \%$ of patients seen in our gastroenterology clinic were excluded on this criterion. These selection biases may limit generalisation to other persons with IBS.

More women than men were seen in our sample of C-IBS patients, although the total IBS sample was sex-balanced. There is considerable evidence of a predominance of women with C-IBS type symptoms in other reports [37,38], although this is not invariably found [39]. Our sample did contain more men than women with pre-treatment SAnD; however there was no significant impact of sex on BDI or STAI, and SSP data is sex-adjusted. Post-hoc analysis of the baseline demographic data is otherwise unremarkable.

The BDI and STAI scales were chosen due to their common use in this field and the availability of these data; nevertheless we are aware of the potential for symptom overlap with somatic symptoms of IBS. 

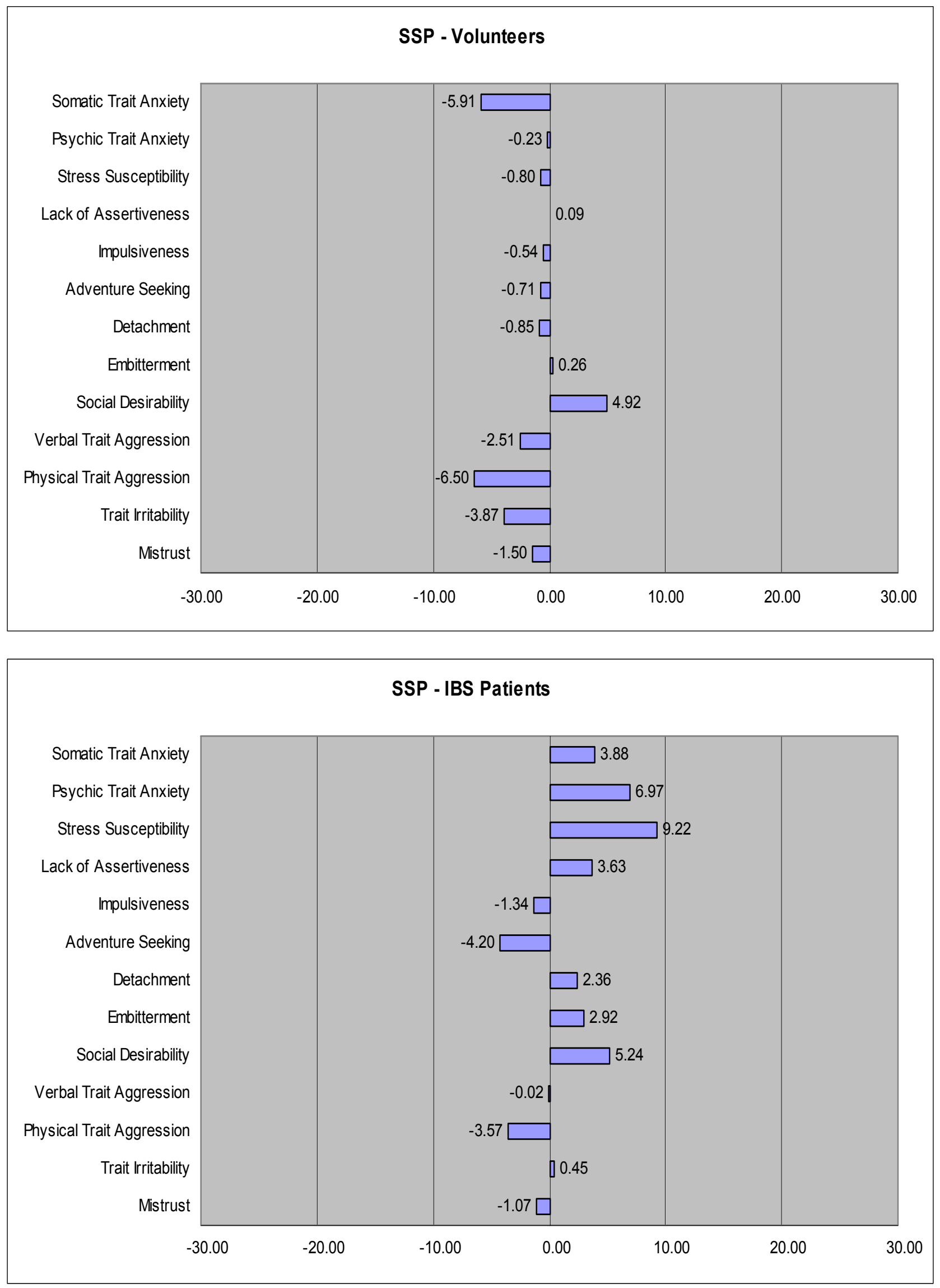
(Fig. 4) contd.....
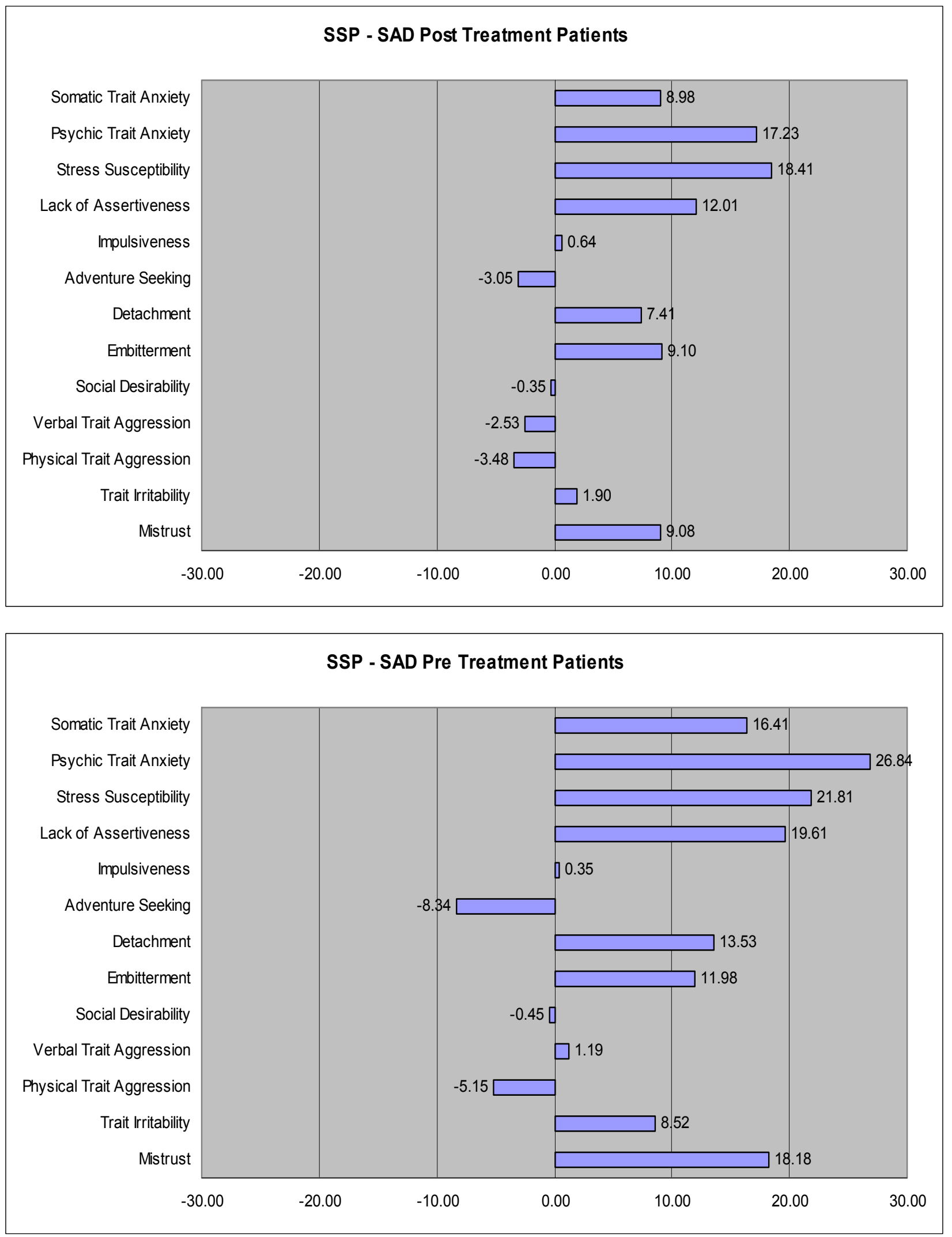

Fig. (4). Average SSP T-Scores. 
The factor analysis may be underpowered. There is little consensus in this area, as although some authors recommend that the subjects-to-variables ratio should be no lower than 5 (ie: $n=75$ ) [24] or that there should be 51 more cases than the number of variables, to support $X^{2}$ testing (ie: $\mathrm{n}=63$ ) [40], others recommend up to 300 cases [41].

\section{CONCLUSION}

In conclusion, we have used the SSP questionnaire and the other measures presented here to describe the psychological profiles of patients with IBS in comparison with both a normal volunteer group and a group of patients with an anxiety disorder. We have shown that patients with IBS presenting to a gastroenterology service have anxiety scores that are intermediate between that seen in patients with a syndromal anxiety disorder and that of normal volunteers. Further, character traits as assessed by the SSP reflect those seen in patients with a DSM-IV anxiety disorder with levels of somatic trait anxiety, psychic trait anxiety and stress susceptibility being intermediate between untreated patients with social anxiety disorder and normal volunteers. Despite this intermediate status, IBS patients as a group had normal SSP profiles. This may suggest that the depressive and anxious tendency of IBS subjects are not related to personality factors, although such a finding is speculative. IBS subtypes differed only with respect to the Lack of Assertiveness variable, which is a finding of uncertain clinical relevance that would benefit from replication in future studies.

It is also clear that whilst pharmacological treatment of patients with anxiety disorders is associated with improved anxiety ratings, the residual level of psychological impairment as defined by these scales still differed significantly from normal volunteers. It would be interesting to see whether successful treatment of patients with IBS normalise these scores and whether stress susceptibility is characterised by altered HPA and autonomic axes responses to appropriate challenge tests. Studies to investigate this are currently underway and we look forward to ongoing refinement of this understanding in future publications.

\section{ACKNOWLEDGEMENT}

Parts of this study have been sponsored by an Avon and Wiltshire Mental Health Partnership NHS Trust Small Project Grant.

\section{REFERENCES}

[1] Saito YA, Schoenfeld P, Locke GR, III. The epidemiology of irritable bowel syndrome in North America: a systematic review. Am J Gastroenterol 2002; 97(8): 1910-5.

[2] Lydiard RB. Irritable bowel syndrome, anxiety, and depression: What are the links? J Clin Psychiatry 2001; 62(Suppl 8): 38-45.

[3] Henningsen P, Zimmerman T, Sattel H. Medically unexplained physical symptoms, anxiety, and depression: A meta-analytic review. Psychosom Med 2003 20; 65(4): 528-33.

[4] Blanchard EB, Keefer L, Galovski TE, Taylor AE, Turner SM. Gender differences in psychological distress among patients with irritable bowel syndrome. J Psychosom Res 2001; 50(5): 271-5.

[5] Heaton KW, Creed F, Mayou R. What makes people with abdominal pain consult their doctor? London: Royal College of Psychiatrists and Royal College of Physicians; 1992.

[6] Drossman DA, McKee DC, Sandler RS, et al. Psychosocial factors in the irritable bowel syndrome. A multivariate study of patients and nonpatients with irritable bowel syndrome. Gastroenterology 1988; 95(3): 701-8.

[7] Mayer EA, Craske M, Naliboff BD. Depression, anxiety, and the gastrointestinal system. J Clin Psychiatry 2001; 62(Suppl 8): 28-36.

[8] Solmaz M, Kavuk I, Sayar K. Psychological factors in the irritable bowel syndrome. Eur J Med Res 2003; 8(12): 549-56.

[9] Talley NJ, Boyce P, Jones M. Dyspepsia and health care seeking in a community: How important are psychological factors? Dig Dis Sci 1998; 43(5): 1016-22.

[10] Weinryb RM, Osterberg E, Blomquist L, Hultcrantz R, Krakau I, Asberg M. Psychological factors in irritable bowel syndrome: a population-based study of patients, non-patients and controls. Scand J Gastroenterol 2003; 38(5): 503-10.

[11] Tack J, Broekaert D, Fischler B, Van OL, Gevers A, Janssens J. A controlled cross-over study of the selective serotonin reuptake inhibitor citalopram in irritable bowel syndrome. Gut 2006; 55(8): 1095-103.

[12] Hutton J. Cognitive behaviour therapy for irritable bowel syndrome. Eur J Gastroenterol Hepatol 2005; 17(1): 11-4.

[13] Argyropoulos SV, Hood SD, Adrover M, et al. Tryptophan depletion reverses the therapeutic effect of selective serotonin reuptake inhibitors in social anxiety disorder. Biol Psychiatry 2004; 56(7): 503-9.

[14] Hood SD, Potokar J, Davies SJ, et al. Dopaminergic challenges in social anxiety disorder: evidence for dopamine D3 desensitisation following successful treatment with serotonergic antidepressants. J Psychopharmacol 2008; in press.

[15] Mearin F, Balboa A, Badia X, et al. Irritable bowel syndrome subtypes according to bowel habit: revisiting the alternating subtype. Eur J Gastroenterol Hepatol 2003; 15(2): 165-72.

[16] Beck AT, Steer RA. Beck Depression Inventory Manual. San Antonio, TX: The Psychological Corporation, Harcourt Brace Jovanovic; 1987.

[17] Spielberger CD, Gorsuch RL, Lushene R, Vagg PR, Jacobs GA. Manual for the State-Trait Anxiety Inventory. Palo Alto, CA: Consulting Psychologists' Press; 1983.

[18] Gustavsson J, Bergman H, Edman G, Ekselius L, von Knorring L, Linder J. Swedish universities Scales of Personality (SSP): construction, internal consistency and normative data. Acta Psychiatr Scand 2000; 102: 217-25.

[19] Schalling D. Contributions to the validation of some personality concepts. Department of Psychology, Stockholm University; 1970.

[20] Eysenck H, Eysenck M. Personality and individual differences: a natural science approach. New York: Plenum Press; 1985.

[21] Mattsson P, Ekselius L. Migraine, major depression, panic disorder, and personality traits in women aged $40-74$ years: a population-based study. Cephalalgia 2002; 22: 543-51.

[22] Spiegelhalter D, Abrams K, Myles J. Bayesian Approaches to Clinical Trials and Health-Care Evaluation (Statistics in Practice). London: John Wiley \& Sons; 2004.

[23] Willebrand M, Kildal M, Andersson G, Ekselius L. Long-term assessment of personality after burn trauma in adults. J Nervous Mental Dis 2002; 190(1): 53-6.

[24] Bryant FB, Yarnold PR. Principal components analysis and exploratory and confirmatory factor analysis. In: Grimm LG, Yarnold PR, Eds. Washington: American Psychological Association Books; 1995; pp. 99-109.

[25] Bennett EJ, Tennant CC, Piesse C, Badcock C-A, Kellow JE. Level of chronic life stress predicts clinical outcome in irritable bowel syndrome. Gut 1998; 43(2): 256-61.

[26] Masand PS, Gupta S, Schwartz TL, et al. Does a preexisting anxiety disorder predict response to paroxetine in irritable bowel syndrome? Psychosomatics 2002; 43(6): 451-5.

[27] Lackner JM, Quigley BM, Blanchard EB. Depression and abdominal pain in IBS patients: the mediating role of catastrophizing. Psychosom Med 2004; 66(3): 435-41.

[28] Crane C, Martin M, Johnston D, Goodwin GM. Does depression influence symptom severity in irritable bowel syndrome? Case study of a patient with irritable bowel syndrome and bipolar disorder. Psychosom Med 2003; 65(5): 919-23.

[29] Damberg M, Berggard C, Mattila-Evenden M, et al. Transcription factor AP-2beta genotype associated with anxiety-related personality traits in women. A replication study. Neuropsychobiology 2003; 48(4): 169-75. 
[30] Jonsson EG, Damberg M, Forslund K, et al. No association between a transcription factor Activating Protein 2beta (AP-2beta) gene variant and schizophrenia. Neurosci Lett 2002; 330(3): 290-2.

[31] Jonsson EG, Burgert E, Crocq MA, et al. Association study between dopamine D3 receptor gene variant and personality traits. Am J Med Genet 2003; 117B(1): 61-5.

[32] Hood SD. Personal Communication with Gustavsson P. 4-8-2003.

[33] Martin M, Crane C. Cognition and the body: Somatic attributions in irritable bowel syndrome. Behav Cogn Psychother 2003; 31(1): 13-31.

[34] De Gucht V, Fischler B, Heiser W. Job stress, personality, and psychological distress as determinants of somatization and functional somatic syndromes in a population of nurses. Stress Health 2003; 19(4): 195-204.

[35] $\mathrm{Hu}$ WH, Wong WM, Lam CL, et al. Anxiety but not depression determines health care-seeking behaviour in Chinese patients with dyspepsia and irritable bowel syndrome: a population-based study. Aliment Pharmacol Ther 2002; 16(12): 2081-8.
[36] Guthrie E, Creed F, Fernandes L, et al. Cluster analysis of symptoms and health seeking behaviour differentiates subgroups of patients with severe irritable bowel syndrome. Gut 2003; 52(11): 1616-22.

[37] Talley NJ, Zinsmeister AR, Melton LJ, III. Irritable bowel syndrome in a community: symptom subgroups, risk factors, and health care utilization. Am J Epidemiol 1995; 142(1): 76-83.

[38] Stewart WF, Liberman JN, Sandler RS, et al. Epidemiology of constipation (EPOC) study in the United States: relation of clinical subtypes to sociodemographic features. Am J Gastroenterol 1999; 94(12): 3530-40.

[39] Gwee KA, Wee S, Wong ML, Png DJ. The prevalence, symptom characteristics, and impact of irritable bowel syndrome in an asian urban community. Am J Gastroenterol 2004; 99(5): 924-31.

[40] Lawley DN, Maxwell AE. Factor analysis as a statistical method. London: Butterworth and Co.; 1971.

[41] Hutcheson G, Sofroniou N. The multivariate social scientist: Introductory statistics using generalized linear models. Thousand Oaks, CA: Sage Publications; 1999.

(C) Hood et al.; Licensee Bentham Open.

This is an open access article licensed under the terms of the Creative Commons Attribution Non-Commercial License (http://creativecommons.org/licenses/by$\mathrm{nc} / 3.0 /$ ) which permits unrestricted, non-commercial use, distribution and reproduction in any medium, provided the work is properly cited. 